\title{
Secondhand tobacco smoke in bars and restaurants in Santiago, Chile: evaluation of partial smoking ban legislation in public places
}

\author{
Marcia Erazo, ${ }^{1}$ Veronica Iglesias, ${ }^{2}$ Andrea Droppelmann, ${ }^{3}$ Marisol Acuña, ${ }^{4}$ \\ Armando Peruga, ${ }^{5}$ Patrick N Breysse, ${ }^{6}$ Ana Navas-Acien ${ }^{6}$
}

${ }^{1}$ Faculty of Medicine, University of Chile, Chile

${ }^{2}$ School of Public Health, University of Chile, Chile

${ }^{3}$ Laboratory of Occupational Health, Institute of Public Health, Chile

${ }^{4}$ Tobacco Control Unit, Ministry of Health, Chile

${ }^{5}$ National Capacity Building Unit, Tobacco Control Program, World Health Organization

${ }^{6}$ Departments of Environmental Health Sciences and Epidemiology, and Institute for Global Tobacco Control, Johns Hopkins University, Bloomberg School of Public Health, USA

\section{Correspondence to}

Dr Marcia Erazo B, Faculty of Medicine, University of Chile, Independencia 1027, Santiago Chile; merazo@med.uchile.cl

Received 14 December 2009 Accepted 13 May 2010 Published Online First 25 August 2010

\section{ABSTRACT}

Objective To compare air nicotine concentrations according to the smoking policy selected by bars/ restaurants in Santiago, Chile before and after the enactment of partial smoking ban legislation in 2007 (establishments could be smoke free, have segregated (mixed) smoking and non-smoking areas, or allow smoking in all areas).

Methods The study measured air nicotine concentrations over 7 days to characterise secondhand smoke exposure in 30 bars/restaurants in 2008. Owner/manager interviews and physical inspections were conducted.

Results Median IQR air nicotine concentrations measured in all venues were $4.38(0.61-13.62) \mu \mathrm{g} / \mathrm{m}^{3}$. Air nicotine concentrations were higher in bars (median 7.22, IQR 2.48-15.64 $\mu \mathrm{g} / \mathrm{m}^{3}$ ) compared to restaurants $\left(1.12,0.15-9.22 \mu \mathrm{g} / \mathrm{m}^{3}\right)$. By smoking status, nicotine concentrations were higher in smoking venues $(13.46$, $5.31-16.87 \mu \mathrm{g} / \mathrm{m}^{3}$ ), followed by smoking areas in mixed venues $\left(9.22,5.09-14.90 \mu \mathrm{g} / \mathrm{m}^{3}\right)$ and non-smoking areas in mixed venues $\left(0.99,0.19-1.27 \mu \mathrm{g} / \mathrm{m}^{3}\right)$. Air nicotine concentrations were markedly lower in smokefree venues $\left(0.12,0.11-0.46 \mu \mathrm{g} / \mathrm{m}^{3}\right)$. After adjustment for differences in volume and ventilation, air nicotine concentrations were 3.2, 35.5 and 56.2 times higher in non-smoking areas in mixed venues, smoking areas in mixed venues and smoking venues, respectively, compared to smoke-free venues.

Conclusions Exposure to secondhand smoke remains high in bars and restaurants in Santiago, Chile. These findings demonstrate that the partial smoking ban legislation enacted in Chile in 2007 provides no protection to employees working in those venues. Enacting a comprehensive smoke-free legislation which protects all people from exposure to secondhand smoke in all public places and workplaces is urgently needed.

\section{INTRODUCTION}

Secondhand tobacco smoke (SHS) is an established cause of death and disease worldwide. ${ }^{1-3}$ In Chile, exposure to secondhand smoke is widespread. Nicotine concentrations in indoor air of public places and workplaces in Santiago were among the highest in Latin America, in particular in restaurants (median $2.08 \mu \mathrm{g} / \mathrm{m}^{3}$ ) and bars (median $\left.3.33 \mu \mathrm{g} / \mathrm{m}^{3}\right){ }^{4}{ }^{5}$ Moreover, approximately $65 \%$ of Chilean high school students reported being exposed to secondhand smoke outside their homes, higher compared to other countries. ${ }^{6} 7$ Protecting the population from exposure to secondhand smoke is urgently needed in Chile.
The WHO Framework Convention on Tobacco Control (WHO FCTC) and its implementation guidelines have clearly indicated that comprehensive smoke-free legislation eliminating tobacco smoking in all indoor public places and workplaces must be implemented to protect all people from the health effects of secondhand smoke. ${ }^{8}$ Chile ratified the WHO FCTC in 2005 and enacted national legislation restricting smoking in public places and workplaces in 2007. 10 The legislation, however, allowed bars and restaurants $<100 \mathrm{~m}^{2}$ for public use to decide their smoking policy (smoke free or smoking) and bars and restaurants $>100 \mathrm{~m}^{2}$ for public use to designate smoking and non-smoking areas physically separated from each other.

In this study, our main goal was to compare levels of secondhand smoke exposure, measured by air nicotine concentrations, in bars and restaurants in Santiago City before and after the implementation of the 2007 Chilean smoking legislation. In addition, we compared air nicotine concentrations according to the smoking policy selected by the venues after the 2007 legislation: smoke free, smoking allowed in all areas, and mixed smoking and non-smoking areas.

\section{METHODS}

\section{Study design and population}

This exposure survey used air nicotine passive samplers to characterise exposure to secondhand smoke in bars and restaurants from Santiago City before (October 2002) and after (April 2008) the implementation of the 2007 tobacco legislation in Chile. In 2002, air nicotine concentrations in bars and restaurants were measured as part of a multicountry study measuring secondhand smoke levels in public places in Latin America. Details on the study protocol have been published previously. ${ }^{4}$ In summary, a total of 10 bars and restaurants participated in 2002 (figure 1). All of them were invited to participate in April 2008. Two of them were no longer in business, one refused and one agreed but the nicotine samplers were lost before removal, leaving six establishments for reassessment of air nicotine concentrations in 2008.

To expand the number of establishments included in the 2008 study, a total of 53 bars and restaurants located in neighbourhoods in Santiago City with a high density of public places where people spend time or gather socially were visited de novo (figure 1). Because the study was part of a larger project, the bar/restaurant needed to have a minimum of two non-smoking workers to be unlocked scheme, see http $/ /$ about/unlocked.xhtml 


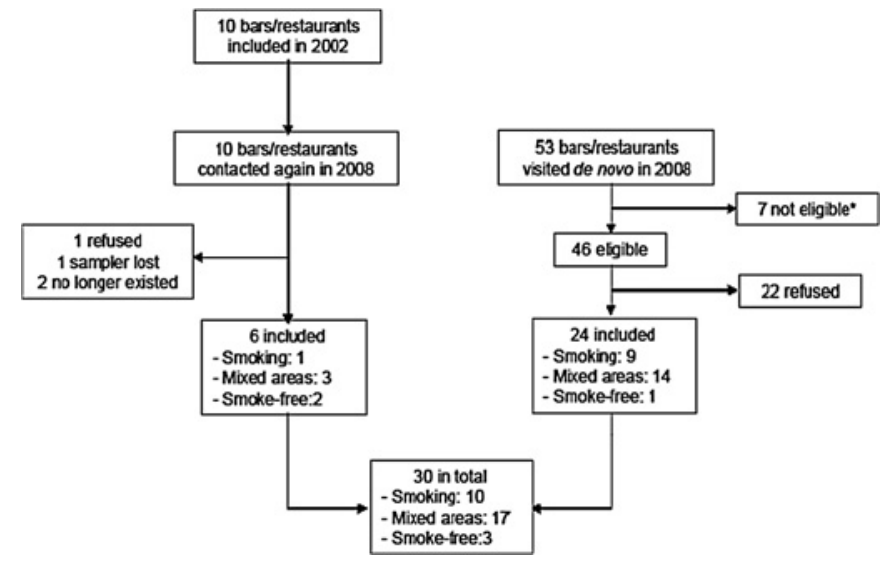

Figure 1 Eligibility criteria of establishments selected de novo in 2008 included having at least two non-smoking employees.

invited to participate $(\mathrm{N}=46)$. Invitation was conducted in person providing a letter with a complete description of the study. Of the 46 eligible venues, 24 agreed to participate (52\% participation rate). Taking together venues evaluated in 2002 and $2008(N=6)$ and venues evaluated only in $2008(N=24)$, a total of 30 bars and restaurants were available for evaluation of secondhand smoke levels by smoking policy in 2008 (10 allowed smoking, 17 had mixed smoking and non-smoking areas and 3 were smoke free). The smoking policy of the establishment was identified by the owner/manager. Participation was voluntary and informed consent was obtained from the responsible authority, owner or manager, of each establishment. The study was approved by the research ethics committee of the School of Medicine, University of Chile.

\section{Data collection}

Short, standardised, interview-based questionnaires administered during work hours but before opening to the public were completed by the owner or manager to collect general characteristics of the venue (number of years in business, size and maximum occupancy, hours of operation, customer and employee demographics, information on food served, dancing space and live music, ventilation systems, smoking policy and estimated percentage of customers who smoked). Room volume was estimated measuring height, length and width of the room with a tape measure. The presence of smoking signs and the separation between smoking and non-smoking areas were observed and recorded.

Time-weighted average concentration of air nicotine was measured using passive samplers originally developed by Hammond and Leaderer. ${ }^{11}$ The samplers were assembled from a 37-mm sampling cassette containing a filter treated with sodium bisulfate and covered by a polycarbonate diffusion membrane at the Secondhand Smoke Exposure Assessment Laboratory of the Johns Hopkins Institute for Global Tobacco Control. In each venue, two nicotine samplers were placed at $1-2 \mathrm{~m}$ from the floor for a total of 7 days (sampling for $24 \mathrm{~h}$ per day). Sample locations were selected to represent the area of the $\mathrm{bar} /$ restaurant that the employees most frequently occupied. In mixed establishments, one sampler was placed in the smoking area and the other in the non-smoking area. In smoking and smoke-free venues, the two samplers were placed in different areas within the venue (eg, one in the bar counter and the other in the tables area). For each sampler, date and time at installation and removal were recorded to estimate overall sampling time. All bars and restaurants were visited once at an hour of maximum public attendance to verify the correct placement of the sampler, the distance of a typical smoker from the sampler, the functioning of ventilation systems, the opening of windows and doors, compliance with smoking restrictions, and the total number of occupants and smokers over a period of $15 \mathrm{~min}$. A total of 2 samplers were lost before removal (1 in a restaurant and 1 in bar) and in 3 venues only 1 sampler was placed, leaving 55 samplers for analysis of air nicotine concentrations.

At the end of the sampling period ( 7 days), the samplers were securely closed, stored in a smoke-free place at room temperature, and transported to the Exposure Assessment Laboratory at Johns Hopkins for the analysis of nicotine content. In the laboratory, the filters were removed from the cassette and the nicotine was extracted in aqueous solution. The nicotine was further extracted and concentrated into a heptane solution and injected into a gas chromatograph with nitrogen detection to increase sensitivity. ${ }^{11}$ The airborne concentration of nicotine was calculated by dividing the amount of nicotine collected by each filter $(\mu \mathrm{g})$ by the volume of air sampled $\left(\mathrm{m}^{3}\right)$. The volume of air sampled was estimated as the total of sampling minutes multiplied by the estimated flow rate $(25 \mathrm{ml} / \mathrm{min})$. A total of 17 samplers had an accompanying duplicate to estimate fieldwork reliability (intraclass correlation coefficient $=0.85$ ). A total of three samplers were field blanks, used to determine blank-corrected nicotine concentrations and to calculate the method limit of detection. The limit of detection was $0.014 \mu \mathrm{g} / \mathrm{m}^{3}$. Two samples had concentrations of nicotine below the detection limit. For these samples, a value half of the detection limit was assigned. Duplicates and blanks were assigned using a fixed random sampling procedure.

In addition, hair nicotine samples within $3 \mathrm{~cm}$ of the hair root were collected from a total of 74 non-smoking employees (33 working in smoking venues, 40 working in smoke-free venues and 4 working in mixed venues). Hair nicotine concentrations (ng/mg) were measured at the Johns Hopkins Assessment Laboratory of the Johns Hopkins Bloomberg School of Public Health. Hair nicotine was extracted using an isotope dilution method (Nicotinine-d3, Supelco, St Louis, Missouri, USA). ${ }^{12}$ Hair nicotine analysis was conducted using gas chromatography/mass spectrometry (GC-17/MS-OP5000, Shimadzu, Columbia, Maryland, USA $)^{13}$ after washing the samples using $3 \mathrm{ml}$ of dichloromethane and sonication (Aquasonic, Model 250HT, Scientific Support, Inc, Hayward, CA 94545) for $30 \mathrm{~min}$ to remove nicotine adhering to the surface of the hair. The limit of detection (LOD) was $0.02 \mathrm{ng} / \mathrm{mg}$ for a $30 \mathrm{mg}$ hair sample. Final hair nicotine concentrations $(\mathrm{ng} / \mathrm{mg}$ ) were provided after subtraction of background levels from blank samples.

\section{Statistical analyses}

For establishments sampled in 2002 and 2008, air nicotine concentrations were compared before and after the 2007 legislation considering the smoking policy of the establishment in both time periods. Crude geometric means $(95 \% \mathrm{CI})$ of air nicotine concentrations by different bar/restaurant characteristics were estimated for establishments sampled in 2008. To compare air nicotine concentrations by smoking policy and other characteristics, we computed crude and multivariable adjusted ratios of the geometric mean and its $95 \% \mathrm{CI}$ using linear regression models on log-transformed nicotine. Analyses were conducted using Stata V.10.1 (Stata, College Station, Texas, USA).

\section{RESULTS}

For establishments sampled in 2002 and $2008(\mathrm{n}=6)$, the smoking policy remained the same as in 2002 in venues 1 and 4 (table 1), changed from smoking allowed in all areas to mixed 
Table 1 Change in air nicotine concentrations in bars/restaurants before and after the implantation of a partial smoking legislation in Chile in 2007

\begin{tabular}{lllllll}
\hline & 2002 & \multicolumn{5}{l}{$\mathbf{2 0 0 8}$} \\
\cline { 2 - 3 } \cline { 5 - 6 } Venue & Policy & $\begin{array}{l}\text { Air nicotine } \\
\left(\mu \mathbf{g} / \mathbf{m}^{\mathbf{3}}\right)\end{array}$ & & Policy & $\begin{array}{l}\text { Air nicotine } \\
\left(\mu \mathbf{g} / \mathbf{m}^{\mathbf{3}}\right)\end{array}$ & Percentage change \\
\hline 1 & Smoking & 3.68 & & Smoking & 4.52 & $+23 \%$ \\
2 & Smoking & 6.85 & & Mixed & 5.17 & $-25 \%$ \\
3 & Smoking & 3.23 & & Mixed & 3.18 & $-2 \%$ \\
4 & Mixed & 8.35 & Mixed & 7.54 & $-10 \%$ \\
5 & Mixed & 1.58 & & Smoke free & 0.06 & $-97 \%$ \\
6 & Mixed & 0.80 & & Smoke free & 0.12 & $-85 \%$ \\
\hline
\end{tabular}

Air nicotine concentrations reflect the average of two air nicotine samplers in each venue. Policy: smoking, allowed in all areas; mixed, smoking and non-smoking areas; smoke free, smoking not allowed in any area.

areas in venues 2 and 3 , and changed from mixed areas to smokefree areas in venues 5 and 6 . Comparing secondhand smoke measured in 2008 versus 2002, air nicotine concentrations had decreased $85 \%$ and $97 \%$ in the two venues changing to a smokefree policy (in 2008, mean air nicotine concentrations were $0.06 \mu \mathrm{g} / \mathrm{m}^{3}$ in venue 5 and $0.12 \mu \mathrm{g} / \mathrm{m}^{3}$ in venue 6). Changes in air nicotine concentrations in the other venues were minor, ranging from $2 \%$ to $25 \%$ decrease in venues with mixed smoking areas in 2008 and $23 \%$ increase for the venue that still allowed smoking in all areas in 2008.

Among the 30 venues sampled in 2008, 60\% were bars (table 2). Most venues allowing smoking and half of those with mixed areas were bars, while all three smoke-free establishments were restaurants. The median number of years in business was 9 , with small differences by smoking policy. The maximum legal occupancy was smaller in smoking venues (median 135 people) compared to mixed (median 150) and smoke-free (median 155) venues. Venues with mixed smoking policy tended to be larger (public space and total volume) compared to smoking and smokefree venues. More than half of bars and restaurants that allowed smoking had an area for public use larger than $100 \mathrm{~m}^{2}$, the maximum area allowed by the current legislation (median $115 \mathrm{~m}^{2}$, 75th percentile $144 \mathrm{~m}^{2}$ ). In $20 \%$ smoking venues, the owner/manager reported that the customers were on average younger than 30 years old. Despite having a smoke-free policy (as indicated by the owner), the owner of one venue reported that some customers smoked inside. In that venue, mean nicotine concentrations were higher than in the two other smoke-free venues $\left(0.48 \mu \mathrm{g} / \mathrm{m}^{3}\right.$ vs $0.06 \mu \mathrm{g} / \mathrm{m}^{3}$ and $0.12 \mu \mathrm{g} / \mathrm{m}^{3}$, respectively).

Median (IOR) air nicotine concentrations measured in 2008 in all venues were $4.38(0.61-13.62) \mu \mathrm{g} / \mathrm{m}^{3}$ (figure 2$)$. Air nicotine concentrations were higher in bars (median 7.22, IOR $2.48-15.64 \mu \mathrm{g} / \mathrm{m}^{3}$ ) compared to restaurants (median 1.12, IOR $\left.0.15-9.22 \mu \mathrm{g} / \mathrm{m}^{3}\right)$. By smoking status, higher nicotine concentrations were measured in smoking venues (median 13.46, IOR $5.31-16.87 \mu \mathrm{g} / \mathrm{m}^{3}$ ), followed by smoking areas in mixed venues (median 9.22, IOR 5.09-14.90 $\mu \mathrm{g} / \mathrm{m}^{3}$ ) and non-smoking areas in mixed venues (median 0.99 IOR $0.19-1.27 \mu \mathrm{g} / \mathrm{m}^{3}$ ). Air nicotine concentrations were markedly lower in smoke-free venues (median 0.12 , IOR $0.11-0.46 \mu \mathrm{g} / \mathrm{m}^{3}$ ). The maximum nicotine

Table 2 Bar/restaurant characteristics, Santiago, Chile

\begin{tabular}{|c|c|c|c|c|}
\hline & Total $(\mathbf{n}=\mathbf{3 0})$ & Smoking $(n=10)$ & Mixed $(n=17)$ & Smoke free $(n=3)$ \\
\hline \multicolumn{5}{|l|}{ Type of venue (\%) } \\
\hline Bar & 60.0 & 90.0 & 52.9 & 0 \\
\hline Restaurant & 40.0 & 10.0 & 47.1 & 100 \\
\hline Surface for public use, $\mathrm{m}^{2 *}$ & $200(130$ to 610$)$ & 115 (93 to 144$)$ & $330(180$ to 420$)$ & 165 (80 to 250$)$ \\
\hline Total volume, $\mathrm{m}^{3 *}$ & 232 (176 to 403$)$ & $214(171$ to 331$)$ & $238(200$ to 413$)$ & $195(161$ to 480$)$ \\
\hline No. of employees* & $25(16$ to 50$)$ & $18(13$ to 25$)$ & $19(15$ to 50$)$ & $45(13$ to 70$)$ \\
\hline \multicolumn{5}{|l|}{ Mean number of customers per day* } \\
\hline Weekdays & $125(70.0$ to 390.0$)$ & 90 (50 to 100$)$ & 100 (70 to 250$)$ & 200 (55 to 900$)$ \\
\hline Weekend days & $200(150$ to 435$)$ & $188(150$ to 200$)$ & $200(120$ to 400$)$ & $200(110$ to 500$)$ \\
\hline \multicolumn{5}{|l|}{ Windows facing outdoors, \% } \\
\hline Yes & 70.0 & 90.0 & 61.1 & 66.7 \\
\hline \multicolumn{5}{|l|}{ Ventilation system, \% } \\
\hline Yes & 48.8 & 71.4 & 38.9 & 0.0 \\
\hline \multicolumn{5}{|c|}{ Tobacco advertisement/promotion present, \% } \\
\hline Yes & 70.0 & 20.0 & 94.1 & 0.0 \\
\hline \multicolumn{5}{|l|}{ Age of customers, $\%$} \\
\hline$<30$ & 6.7 & 20.0 & 0.0 & 0.0 \\
\hline$>30$ & 40.0 & 50.0 & 41.2 & 0.0 \\
\hline All ages $†$ & 53.3 & 30.0 & 58.8 & 100 \\
\hline \multicolumn{5}{|l|}{ Customers smoking inside, \%‡: } \\
\hline Nobody & 6.7 & 0.0 & 70.6 & 66.7 \\
\hline$<50 \%$ of customers & 43.3 & 0.0 & 0.0 & 33.3 \\
\hline$>50 \%$ of customers & 50.0 & 100 & 29.4 & 0.0 \\
\hline $\begin{array}{l}\text { Hair nicotine level in non-smoking } \\
\text { employees, } \mathrm{ng} / \mathrm{mg}^{*}\end{array}$ & $2.00(0.81$ to 6.18$)$ & $2.62(0.83$ to 6.22$)$ & $1.80(0.81$ to 5.75$)$ & 1.24 (0.68 to 7.63 ) \\
\hline
\end{tabular}

*Median and IQR

†Including children.

$\ddagger$ For mixed venues, this question was answered with respect to the non-smoking area only. 
Figure 2 Air nicotine concentrations in Santiago, Chile 2008, overall, by bar/ restaurant status and by smoking policy as reported by the owner/manager.

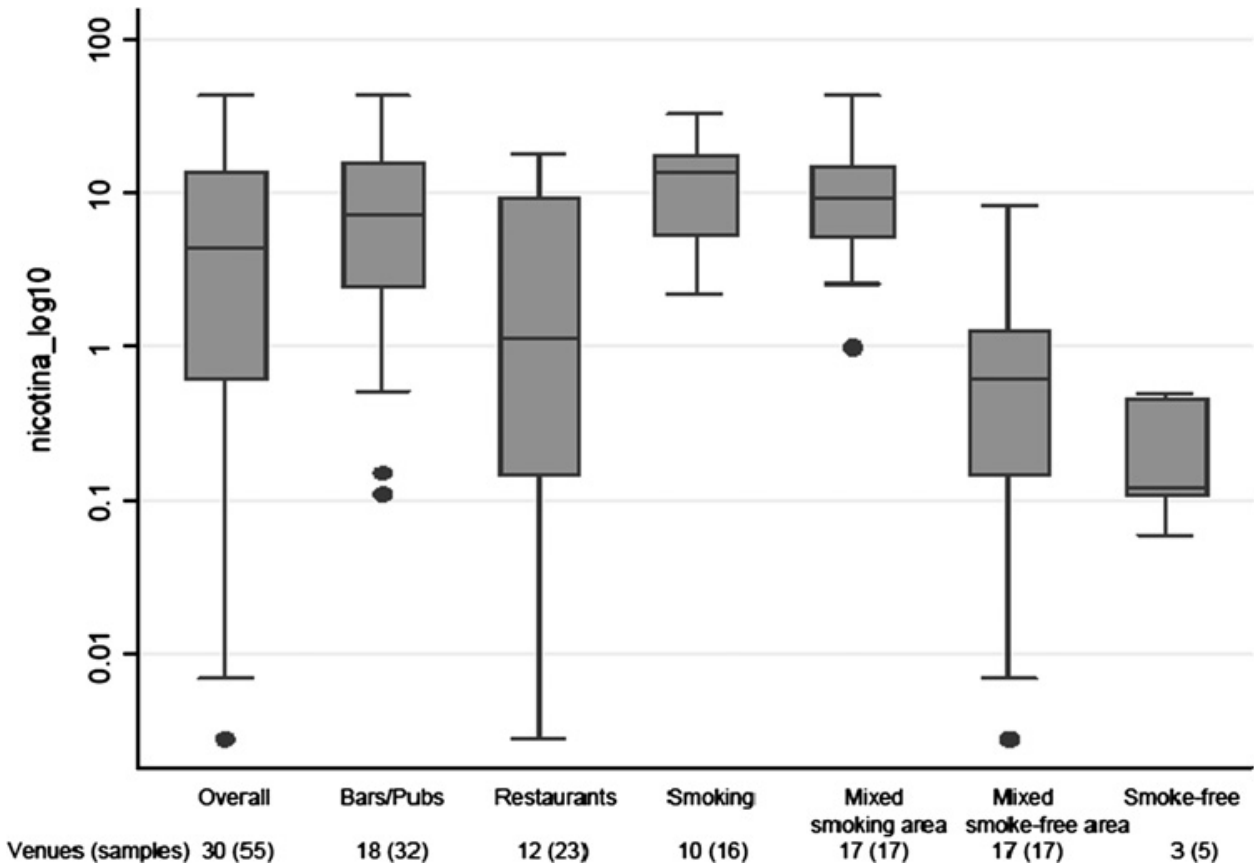

concentration $\left(37.19 \mu \mathrm{g} / \mathrm{m}^{3}\right)$ occurred in a bar that allowed smoking in all areas. Hair nicotine concentrations were also higher in non-smoking employees working in smoking (median $2.62 \mathrm{ng} / \mathrm{mg}$ ) and mixed venues (median $1.80 \mathrm{ng} / \mathrm{mg}$ ) compared to smoke-free venues (median $1.24 \mathrm{ng} / \mathrm{mg}$ ) (table 2).

Compared to smoke-free venues, air nicotine concentrations were 3.2 times higher in non-smoking areas of mixed venues, 35.5 times higher in smoking areas of mixed venues and 56.2 times higher in venues that allowed smoking in all areas, after adjustment for differences in volume and ventilation (table 3).
A clear dose response with increasing air nicotine concentrations was also observed with increasing \% of customers smoking indoors, as reported by the owner/manager.

\section{DISCUSSION}

\section{Summary of findings}

Exposure to secondhand tobacco smoke remains high in bars and restaurants in Santiago, Chile that allow smoking in all areas or with mixed smoking and non-smoking areas after the enactment of a partial smoking ban legislation in 2007. Compared to

Table 3 Ratios (95\% Cl) of geometric mean of air nicotine concentration by bar/restaurant characteristics

\begin{tabular}{|c|c|c|c|c|c|}
\hline Bar/restaurant characteristic & No. of venues & No. of samples & Geometric mean (95\% CI) & Crude ratio $(95 \% \mathrm{CI})$ & Adjusted ratio $(95 \% \mathrm{CI})$ \\
\hline \multicolumn{6}{|l|}{ Smoking status of the venue* } \\
\hline Smoke free & 3 & 5 & $0.18(0.08$ to 0.41$)$ & 1.0 (reference) & 1.0 (reference) \\
\hline Mixed: smoke-free area & 17 & 17 & $0.60(0.28$ to 1.29$)$ & $3.31(0.75$ to 14.68$)$ & $3.24(0.70$ to 15.01$)$ \\
\hline Mixed: smoking area & 17 & 17 & $6.45(2.61$ to 15.92$)$ & $36.3(8.19$ to 161.0$)$ & $35.5(7.56$ to 164.6$)$ \\
\hline Smoking & 10 & 16 & $10.47(7.29$ to 15.02$)$ & $58.9(13.3$ to 261.1$)$ & 56.2 (12.1 to 260.9$)$ \\
\hline \multicolumn{6}{|l|}{ Type of venue* } \\
\hline Restaurant & 12 & 23 & $0.97(0.37$ to 2.52$)$ & 1.0 (reference) & 1.0 (reference) \\
\hline Bar/pub & 18 & 32 & $5.24(3.19$ to 8.62$)$ & $5.25(1.86$ to 14.8$)$ & $6.17(2.18$ to 17.4$)$ \\
\hline \multicolumn{6}{|l|}{ Customers smoking inside $(\%)^{*}$} \\
\hline Nobody & 2 & 3 & $0.09(0.06$ to 0.14$)$ & 1.0 (reference) & 1.0 (reference) \\
\hline$<50 \%$ of the customers & 13 & 22 & $1.44(0.64$ to 3.25$)$ & $15.9(1.90$ to 132.2$)$ & $5.49(0.37$ to 82.4$)$ \\
\hline$>50 \%$ of the customers & 15 & 30 & $6.60(4.02$ to 10.85$)$ & 72.4 (8.69 to 604.2$)$ & $10.7(0.60$ to 192.5$)$ \\
\hline \multicolumn{6}{|l|}{ Windows facing outdoors* } \\
\hline No & 9 & 16 & 1.99 (0.80 to 4.92$)$ & 1.0 (reference) & 1.0 (reference) \\
\hline Yes & 21 & 39 & $2.81(1.43$ to 5.54$)$ & 1.45 (0.53 to 4.89$)$ & $0.95(0.39$ to 2.36$)$ \\
\hline \multicolumn{6}{|l|}{ Ventilation system $† \S$} \\
\hline No & 2 & 4 & 8.51 (2.88 to 25.14$)$ & 1.0 (reference) & 1.0 (reference) \\
\hline Yes & 28 & 51 & 2.34 (1.36 to 4.02$)$ & $0.27(0.03$ to 2.24$)$ & $1.26(0.23$ to 6.99$)$ \\
\hline \multicolumn{6}{|l|}{ Air conditioning $\dagger$} \\
\hline No & 12 & 22 & 5.12 (2.85 to 9.22$)$ & 1.0 (reference) & 1.0 (reference) \\
\hline Yes & 18 & 33 & $1.62(0.75$ to 3.49$)$ & $0.31(0.10$ to 0.91$)$ & $0.69(0.29$ to 1.63$)$ \\
\hline \multicolumn{6}{|l|}{ Volume $\ddagger$} \\
\hline$<289 \mathrm{~m}^{3}$ & 15 & 27 & 2.51 (1.11 to 5.66$)$ & 1.0 (reference) & 1.0 (reference) \\
\hline$>289 \mathrm{~m}^{3}$ & 15 & 28 & 2.57 (1.24 to 5.29$)$ & $1.02(0.33$ to 3.15$)$ & $0.95(0.40$ to 2.25$)$ \\
\hline
\end{tabular}

${ }^{*}$ Adjusted for volume of the venue, smoking status of the venue and ventilation.

tAdjusted for volume of the venue and smoking status of the venue.

$\ddagger$ Adjusted for ventilation of the venue and smoking status of the venue.

§Included air extractor and ventilator. 
2002, marked reductions in air nicotine concentrations (85\% reduction or higher) were only observed in venues that adopted a smoke-free policy. In bars and restaurants with mixed policy, concentrations in non-smoking areas were three times higher than in smoke-free restaurants, possibly through contamination from the smoking areas, supporting the conclusion that the barrier systems implemented were insufficient to eliminate exposure to tobacco smoke. More importantly, employees working in bars and restaurants with mixed policies were exposed to levels of secondhand smoke as high as those measured in bars and restaurant where smoking was allowed. Finally, none of the bars visited were smoke free and in one restaurant with a smoke-free policy the owner reported that some customers still smoked inside. These findings highlight the challenge of implementing voluntary smoke-free policies in the presence of partial smoking ban legislations.

\section{Comparison with other countries}

Air nicotine concentrations measured in this study were similar or higher than those measured in bars and restaurants from other Latin American countries ${ }^{5}$ but lower compared to European countries without smoke-free legislations. ${ }^{14}$ The concentrations of secondhand smoke measured in bars and restaurants of Santiago could be related to higher smoking prevalence compared to many countries in Latin America but less cigarettes per day smoked compared to most countries in Europe.

Compared to 2002, air nicotine concentrations in 2008 were markedly reduced in venues that had adopted smoke-free policies on a voluntary basis but not in those that still allowed smoking in all or restricted areas. These findings are consistent with marked reductions in air nicotine concentrations in bars and restaurants in Ireland, ${ }^{15}$ Norway ${ }^{16}$ and Uruguay ${ }^{17}$ after the implementation of comprehensive smoke-free legislations, and with no changes over time in Austria and other European countries with no legislation or only partial legislations. ${ }^{18} 19$ Indeed, the smoking policy and level of enforcement in bars and restaurants is the main determinant of air nicotine concentrations. $^{20} 21$ Ventilation measures, including advanced ventilation technology, are unable to reduce secondhand tobacco smoke and protect employees and customers from elevated risk of cancer, respiratory and cardiovascular disease. ${ }^{22}$ In our study, after adjustment for smoking policy, no differences were observed in air nicotine concentrations by ventilation measures (windows facing outdoor and presence of ventilation system). In 2006, a report of the US Surgeon General concluded that the scientific evidence has consistently shown that mechanical systems and separated areas cannot protect the population from exposure to tobacco smoke. ${ }^{3}$

\section{Importance of smoke-free legislations}

The high levels of secondhand tobacco smoke measured in bars and restaurants with smoking or mixed policies in this study reinforce the need to enact a comprehensive smoke-free legislation in Chile. The FCTC and its implementation guidelines have clearly established that only smoke-free legislations that eliminate tobacco smoke in all public places can protect all people, including workers, from exposure to tobacco smoke. ${ }^{8}$ Comprehensive smoke-free legislation protects non-smokers from the health consequences of secondhand smoke. ${ }^{23}$ Short-term benefits of smoke-free legislations include important reductions in hospital admissions for acute coronary events and improvements in respiratory health. ${ }^{24-29}$

Smoke-free legislation motivates smokers to quit ${ }^{30-33}$ and reduce the number of people initiating smoking. ${ }^{34}$ In our study, most venues that allowed smoking were bars and tended to have younger customers. The implementation of smoke-free legislations in places where young people gather and spend time is thus a critical public health issue. Also, conversely to the complexities of implementing partial smoking legislations observed in our study, comprehensive smoke-free legislations are easier to implement and enforce, as shown for instance in Ireland, ${ }^{15}$ Norway ${ }^{16}$ and Uruguay. ${ }^{17}$ Comprehensive smoke-free legislations, moreover, cause no economic damage to the hospitality sector ${ }^{35} 36$ and are largely supported by most populations worldwide. ${ }^{37-39}$

\section{Limitations and strengths}

Nicotine measurements were available only in bars/restaurants that accepted to participate in the study. While sampling was not conducted at random, venues were selected using a door-todoor technique in neighbourhoods with a high concentration of bars and restaurants in Santiago. Underestimation of air nicotine concentrations is possible if venues refusing to participate had more customers who smoked compared to participating venues. For large venues with mixed areas, it is also possible that places with incomplete or poor enforcement of the legislation were less likely to participate.

An important strength of this study is the assessment of secondhand smoke exposure measuring airborne concentrations of nicotine, a specific tracer that is commonly used as a surrogate for other toxic and carcinogenic components in tobacco. Measuring air nicotine concentrations allowed us to precisely quantify secondhand smoke exposure levels, comparing them to previous measures in Chile and in other countries. ${ }^{4}{ }^{14}$ Furthermore, the laboratory was masked with respect to the smoking policy of the venue, minimising the risk of information bias. Finally, sampling was conducted during similar seasonal periods, reducing potential changes in air nicotine concentrations due to differences in outdoor smoking and ventilation patterns.

\section{Conclusions}

Our study confirms that the partial smoking ban legislation enacted in Chile in 2007 provides no protection from secondhand smoke exposure to employees and customers in bars and restaurants that opted for allowing smoking in all areas or for having separated smoking and non-smoking areas. Moreover, some of the smoke-free venues found it hard to ensure complete customer compliance. This could be related to a perception that the legislation is not seriously trying to reduce exposure to SHS or because of difficulties in educating the public to comply with legislation that establishes multiple and often complex conditions. In addition, no official enforcement mechanisms and

\section{What this paper adds}

- Exposure to secondhand smoke remains high in bars and restaurants in Santiago, Chile, despite the implementation of partial smoking ban legislation in 2007.

- These findings provide evidence that partial smoking ban legislation provides no protection for employees working in venues where smoking is allowed.

- There is urgent need to replace the current legislation by a comprehensive smoke-free legislation that fully protects all people and workers from exposure to secondhand smoke in public places. 
sanctions are available for venues that voluntarily decide to become smoke free. Comprehensive smoke-free legislation is the best policy ${ }^{3}$ and the international standard ${ }^{8}$ to eliminate exposure to secondhand smoke in indoor public places and workplaces. Chile is currently not complying with article 8 of the FCTC. The Conference of the Parties guidelines recommend that comprehensive smoke-free legislations are in place within 5 years of entry into force of the FCTC for a particular Party. For Chile, this date is due by June 2010. Short-term and long-term health benefits from directly protecting non-smokers (especially bar and restaurant workers who spend many hours in their workplace) and indirectly reducing smoking prevalence and incidence are authoritative reasons to urgently enact and successfully implement a comprehensive smoke-free legislation in Chile.

Acknowledgements We thank Dr Kyle Steenland from Emory University and Dr Paulina Pino from University of Chile for their support and feedback in the conduction of this study, Drs Cecilia Orellana and Paulina Aceituno for their important contributions to the field work and Chrissy Torrey and Jie Yuan for their nicotine analytical support.

Funding This study was supported by a US National Institutes of Health Fogarty Grant (number: D43 TW 05746-02) and a Clinical Investigator Award from the Flight Attendant Medical Research Institute.

Competing interests None declared.

Patient consent Obtained.

Ethics approval This study was conducted with the approval of the Faculty of Medicine, University of Chile.

Provenance and peer review Not commissioned; externally peer reviewed.

\section{REFERENCES}

1. Stayner L, Bena J, Sasco AJ, et al. Lung cancer risk and workplace exposure to environmental tobacco smoke. Am J Public Health 2007;97:545-51.

2. Centers for Disease Control and Prevention. Smoking-attributable mortality, years of potential life lost, and productivity losses-United States, 2000-2004. MMWR Morb Mortal Wkly Rep 2008;57:1226-8.

3. US Department of Health and Human Services. The health consequences of involuntary exposure to tobacco smoke: a report of the surgeon general. Atlanta GA: US Department of Health and Human Services, Centers for Disease Control and Prevention, Coordinating Center for Health Promotion, National Center for Chronic Disease Prevention and Health Promotion, Office on Smoking and Health, 2006.

4. Navas-Acien A, Peruga A, Breysse P, et al. Secondhand tobacco smoke in public places in Latin America, 2002-2003. JAMA 2004;291:2741-5.

5. Barnoya J, Mendoza-Montano C, Navas-Acien A. Secondhand smoke exposure in public places in Guatemala: comparison with other Latin American countries. Cancer Epidemiol Biomarkers Prev 2007;16:2730-5.

6. Anon. National committee to control drug consumption (CONACE). 7th National survey in general population. 2006. http://www.conacedrogas.cl/inicio/pdf/ bd928b266121a764e5ea61e6e6ab2ba3.pdf (accessed 5 Aug 2009).

7. GTSS Collaborative Group. A cross country comparison of exposure to secondhand smoke among youth. Tob Control 2006;15(Suppl 2):ii4-19.

8. World Health Organization. Elaboration of guidelines for implementation of the Convention (decision FCTC/COP1(15)) Article 8: Protection from exposure to tobacco smoke. 2007. http://apps.who.int/gb/fctc/PDF/cop2/FCTC_COP2_7-en.pdf laccessed 5 Aug 2009).

9. Acuña M, Bello S. El Convenio Marco de la OMS para el Control del Tabaco: Un instrumento jurídico al servicio de la salud pública mundial. Rev Chil Enf Respir 2003;19:143-5.

10. National Congress of Chile Ministry of Health of Chile. Law number 20105. 2006. http://www.bibliodrogas.cl/biblioteca/digital/LEY20DEL20TABAC02020105.pdf (accessed 5 Aug 2009)

11. Hammond SK, Leaderer BP. A diffusion monitor to measure exposure to passive smoking. Environ Sci Technol 1987;21:494-7.

12. Kim SR, Wipfli H, Avila-Tang E, et al. Method validation for measurement of hair nicotine level in nonsmokers. Biomed Chromatogr 2009;23:273-9.
13. Kintz P. Gas chromatographic analysis of nicotine and cotinine in hair. J Chromatogr 1992; 580:347-53.

14. Nebot M, López MJ, Gorini G, et al. Environmental tobacco smoke exposure in public places of European cities. Tob Control 2005;14:60-3.

15. Mulcahy M, Evans DS, Hammond SK, et al. Secondhand smoke exposure and risk following the Irish smoking ban: an assessment of salivary cotinine concentrations in hotel workers and air nicotine levels in bars. Tob Control 2005;14:384-8.

16. Ellingsen DG, Fladseth $\mathrm{G}$, Daae $\mathrm{HL}$, et al. Airborne exposure and biological monitoring of bar and restaurant workers before and after the introduction of a smoking ban. J Environ Monit 2006;8:362-8.

17. Blanco-Marquizo A, Goja B, Peruga A, et al. Reduction of secondhand tobacco smoke in public places following national smoke-free legislation in Uruguay. Tob Control 2010;19:231-4

18. Gorini G, Moshammer H, Sbrogiò L, et al. Italy and Austria before and after study: second-hand smoke exposure in hospitality premises before and after 2 years from the introduction of the Italian smoking ban. Indoor Air 2008;18:328-34.

19. Lopez MJ, Nebot M, Albertini M, et al. Secondhand smoke exposure in hospitality venues in Europe. Environ Health Perspect 2008;116:1469-72.

20. Marcus BH, Emmons KM, Abrams DB, et al. Restrictive workplace smoking policies: impact on nonsmokers' tobacco exposure. J Public Health Policy 1992:13:42-51.

21. Albers $\mathbf{A B}$, Siegel $\mathrm{M}$, Cheng DM, et al. Effects of restaurant and bar smoking regulations on exposure to environmental tobacco smoke among Massachusetts adults. Am J Public Health 2004;94:1959-64.

22. Repace J. Can ventilation control secondhand smoke in the hospitality industry?, B. M.R. Associates, ed. 2000.

23. Bannon F, Devlin A, McElwee G, et al. Greater gains from smoke-free legislation for non-smoking bar staff in Belfast. Eur J Public Health 2009;19:638-43.

24. Sargent RP, Shepard RM, Glantz SA. Reduced incidence of admissions for myocardial infarction associated with public smoking ban: before and after study. BMJ 2004;328:977-80.

25. Bartecchi C, Alsever RN, Nevin-Woods C, et al. Reduction in the incidence of acute myocardial infarction associated with a citywide smoking ordinance. Circulation 2006;114:1490-6.

26. Ayres JG, Semple S, MacCalman L, et al. Bar workers' health and environmental tobacco smoke exposure (BHETSE): symptomatic improvement in bar staff following smoke-free legislation in Scotland. Occup Environ Med 2009;66:339-46.

27. Larsson M, Boëthius G, Axelsson S, et al. Exposure to environmental tobacco smoke and health effects among hospitality workers in Sweden-before and after the implementation of a smoke-free law. Scand J Work Environ Health 2008;34:267-77.

28. Menzies D, Nair A, Williamson PA, et al. Respiratory symptoms, pulmonary function, and markers of inflammation among bar workers before and after a legislative ban on smoking in public places. JAMA 2006;296:1742-8.

29. Goodman P, Agnew M, McCaffrey M, et al. Effects of the Irish smoking ban on respiratory health of bar workers and air quality in Dublin pubs. Am J Respir Crit Care Med 2007:175:840-5.

30. Fichtenberg $\mathbf{C M}$, Glantz SA. Effect of smoke-free workplaces on smoking behaviour: systematic review. BMJ 2002;325:188.

31. Braverman MT, Aarø LE, Hetland J. Changes in smoking among restaurant and bar employees following Norway's comprehensive smoking ban. Health Promot Int 2008;23:5-15.

32. Fromme H, Kuhn J, Bolte G. Secondhand smoke in hospitality venues. Exposure, body burden, economic and health aspects in conjunction with smoking bans. Gesundheitswesen 2009:71:242-57.

33. Heloma A, Jaakkola MS, Kähkönen $\mathrm{E}$, et al. The short-term impact of national smoke-free workplace legislation on passive smoking and tobacco use. Am J Public Health 2001:91:1416-18

34. Helakorpi S, Martelin T, Torppa J, et al. Did Finland's Tobacco Control Act of 1976 have an impact on ever smoking? An examination based on male and female cohort trends. J Epidemiol Community Health 2004;58:649-54.

35. Alamar B, Glantz SA. Effect of smoke-free laws on bar value and profits. Am J Public Health 2007:97:1400-2.

36. Scollo M, Lal A, Hyland A, et al. Review of the quality of studies on the economic effects of smoke-free policies on the hospitality industry. Tob Control 2003;12:13-20.

37. Heloma A, Jaakkola MS. Four-year follow-up of smoke exposure, attitudes and smoking behaviour following enactment of Finland's national smoke-free work-place law. Addiction 2003;98:1111-17.

38. Borland R, Yong HH, Siahpush M, et al. Support for and reported compliance with smoke-free restaurants and bars by smokers in four countries: findings from the International Tobacco Control (ITC) Four Country Survey. Tob Control 2006;15 (Suppl 3):iii34-41.

39. Hilton S, Semple S, Miller BG, et al. Expectations and changing attitudes of bar workers before and after the implementation of smoke-free legislation in Scotland. BMC Public Health 2007:7:206. 